\title{
Experimental and DFT study of 2-ferrocenylpropan-2-ol cyclodimerization products
}

\author{
Jasmina Lapić, ${ }^{a}$ Mario Cetina, ${ }^{b}$ Davor Šakić, ${ }^{c}$ Senka Djakovićc, ${ }^{a, *}$ Valerije Vrček, ${ }^{c, *}$ and \\ Vladimir Rapića \\ ${ }^{a}$ Department of Chemistry and Biochemistry, Faculty of Food Technology and Biotechnology, \\ University of Zagreb, Pierottijeva 6, HR-10000 Zagreb, Croatia \\ ${ }^{b}$ Department of Applied Chemistry, Faculty of Textile Technology, University of \\ Zagreb, Prilaz baruna Filipovića 28a, HR-10000 Zagreb, Croatia \\ ${ }^{c}$ Department of Organic Chemistry, Faculty of Pharmacy and Biochemistry, University \\ of Zagreb, A. Kovačića 1, HR-10000 Zagreb, Croatia \\ E-mail:sdjakov@pbf.hr,valerije@pharma.hr
}

\begin{abstract}
1,1'-(1-Ferrocenyl-1,3,3-trimethylpropane-1,3-diyl)ferrocene and 1,2-(1-ferrocenyl-1,3,3trimethylpropane-1,3-diyl)ferrocene are formed as cyclodimeric products during the synthesis of $\beta$-ferrocenyl carbinols, in relative ratios which depend on the reaction conditions. Their ratios and stabilities are examined, and calculated at the BP86 level of theory and several different isomers of the homoannular product were examined by DFT calculations.
\end{abstract}

Keywords: Ferrocene, cyclodimeric products, carbinols, DFT calculation

\section{Introduction}

Ferrocenyl alcohols are very useful synthetic intermediates in the synthesis of many biologically active compounds, industrially important compounds, as ligands in homogenous catalysis, in material science (e.g. in nonlinear optics) and in bio-organometallic chemistry as redox-active probes or candidates for drugs. ${ }^{1,2}$ In a previous paper $^{3}$ we studied the nucleophilic substitution of diethyl malonate with $\omega$-ferrocenylalkanols, derived carbinyl acetates, bromides and quaternary salts to $\alpha$-ferrocenylalkylmalonates. These substrates can easily be reduced into the prochiral 2( $\omega$-ferrocenylalkyl)propane-1,3-diols. Furthermore, we examined the enzymatic esterification of these prochiral diols in order to determine a degree of desymmetrization depending on the length of the side chain, i.e., the distance between the ferrocene moiety and stereogenic center. ${ }^{4}$ The compound 4, 1,2-(1-ferrocenyl-1,3,3-trimethylpropane-1,3-diyl)ferrocene, was prepared as a part of our research on bio-catalyzed acylations of secondary $\omega$-ferrocenylalkanols. 
It was shown earlier that secondary ferrocenyl carbinols can be dehydrated to give the corresponding vinyl-ferrocenes which under mild conditions undergo dimerization resulting in linear olefinic products. For example, treatment of 1-ferrocenylethanol with acid-washed alumina in refluxing benzene produces 1,3-diferrocenyl-1-butene. ${ }^{5}$ If the analogous dehydration of secondary ferrocenyl carbinol is performed in more acidic medium (i.e. $40 \% \mathrm{H}_{2} \mathrm{SO}_{4}$ or $90 \%$ $\mathrm{HCOOH})$ no linear dimeric product is obtained; only cyclodimers are formed resulting from homoannular or heteroannular cyclodimerization. ${ }^{6}$ In this work we show that in the case of tertiary ferrocenyl carbinols the only products of acid catalyzed dehydration are cyclodimers. No linear dimeric product has been observed, in either weak or strong acid medium, and the only operative mechanisms are homo- and heteroannular cyclodimerization.

\section{Results and Discussion}

The treatment of 2-ferrocenylpropan-2-ol 1 with $\mathrm{Al}_{2} \mathrm{O}_{3}$ (acid) in benzene formed the ferrocenylalkene 2, 1,1'-(1-ferrocenyl-1,3,3-trimethylpropane-1,3-diyl)ferrocene 3 and 1,2-(1-ferrocenyl1,3,3-trimethylpropane-1,3-diyl)ferrocene 4 (Scheme 1). ${ }^{5,6}$ These compounds resulted from homo-cyclodimerization or hetero-cyclodimerization of 2-ferrocenylprop-1-ene 2, respectively, under acidic conditions. Contrary to the case reported by Iturbide et al. ${ }^{7}$ the main cyclodimeric product is $\mathbf{3}$, with a yield approximately twice as high as that of $\mathbf{4}$. In their case retrocyclization occurs as competitive process upon action of base in DMSO on 2,2-dibromo-1-ferrocenyl-1methylcyclopropane. The more polar solvent they have been using preferentially stabilizes the carbocation intermediates involved in formation of $\mathbf{4}$. In our case the non-polar benzene favors reaction intermediates (leading to formation of 3 ) in which the positive charge is more delocalized (see below). It shows that different reaction conditions can shift the preferred mechanism from homo-cyclodimerization to hetero-cyclodimerization. The linear dimeric product $\mathbf{5}$ has not been obtained, probably due to steric effects.

\section{X-Ray crystal structure analysis}

In order to confirm the rearrangement we proposed, and to determine the exact structure of the dimeric products 3 and $\mathbf{4}$ we tried to obtain single crystals for X-ray crystal structure analysis. Unfortunately, we succeeded in obtaining only a single crystal of compound $4^{7}$ (Figure 1). Neither crystallographic nor spectroscopic data $\left({ }^{13} \mathrm{C}-\mathrm{NMR}\right.$; see below) are known for 3 .

The five-membered ring (C-1/C-2/C-21/C-22/C-23) of 4 is fused to the ferrocene cyclopentadienyl $(\mathrm{Cp})$ ring via common carbon atoms $\mathrm{C}-1$ and $\mathrm{C}-2$. Also, a monosubstituted ferrocenyl moiety, which is oriented in an exo-position with respect to the 1,2-disubstituted $\mathrm{Cp}$ ring, is linked to the five-membered ring. The five-membered ring adopts an envelope conformation, with the $\mathrm{C}-22$ atom displaced above the mean plane of the other ring atoms by $0.352(4) \AA$. 


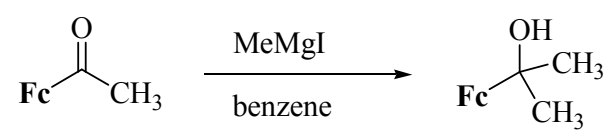

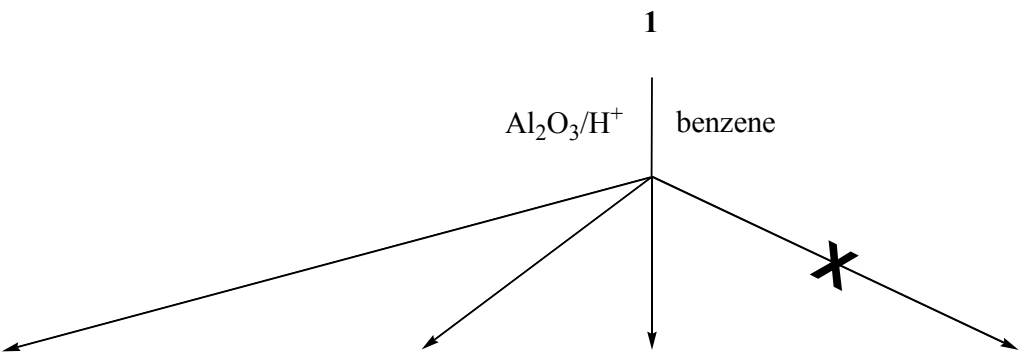

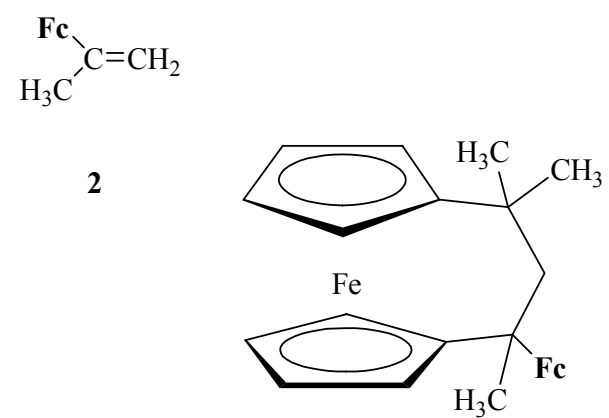

3

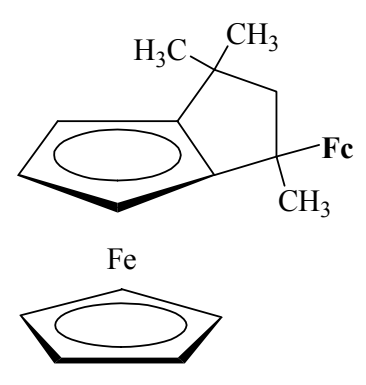

4

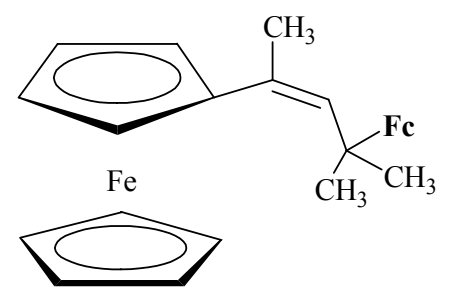

5

\section{Scheme 1}

Figure 1. A molecular structure of 4, with the atom-numbering scheme. Displacement ellipsoids for non-hydrogen atoms are drawn at the $30 \%$ probability level. Selected bond distances $[\AA]$ : C2-C-21 1.504(5); C-21-C-26 1.539(6); C-21-C-11 1.513(5); C-21-C-22 1.569(5); C-22-C23 1.548(6); C-23-C-24 1.540(6); C-23-C-25 1.518(6); C-23-C1 1.513(5). Selected bond angles [ ${ }^{\circ}$ ]: C-2-C-21-C-26 114.5(4); C-2-C-21-C-11 109.9(3); C-2-C-21-C-22 100.4(3); C- 
11-C-21-C-26 111.3(3); C-11-C-21-C-22 110.1(3); C-22-C-21-C-26 110.1(3); C-21-C22-C-23 110.1(3); C-22-C-23-C-24 111.6(4); C-22-C-23-C-25 111.4(4); C-1-C-23-C-22 100.1(3); C-24-C-23-C-25 109.6(4); C-1-C-23-C-24 109.7(3); C-1-C-23-C-25 114.4(3); C$1-\mathrm{C}-2-\mathrm{C}-21$ 111.5(3); C-2-C-1-C-23 112.9(3).

The conformation of the cyclopentadienyl rings in two ferrocenyl moieties is different. The $\mathrm{Cp}$ rings in disubstituted ferrocenyl moiety deviate very slightly from a staggered conformation, whereas in monosubstituted ferrocenyl moiety they deviate very slightly from an eclipsed conformation. The values of the corresponding $\mathrm{C}-\mathrm{Cg}-\mathrm{Cg}-\mathrm{C}$ pseudo-torsion angles, defined by joining two eclipsing $\mathrm{Cp}$ carbon atoms through the ring centroids $(\mathrm{Cg})$, range from 31.8(4) to 32.6(4) and from 2.7(3) to $3.8(4)^{\circ}$ for disubstituted and monosubstituted ferrocenyl moieties, respectively. This could be also demonstrated by a torsion angle defined by the opposite $\mathrm{Cp}$ carbon atoms and the ring centroids which would be $144^{\circ}$ for fully eclipsed conformation and $180^{\circ}$ for staggered conformation. The $\mathrm{C}-1-\mathrm{Cg}-\mathrm{Cg}-\mathrm{C}-9$ and $\mathrm{C}-11-\mathrm{Cg}-\mathrm{Cg}-\mathrm{C}-19$ torsion angles in 4 are 175.9(4) and 147.1(3) ${ }^{\circ}$, respectively.

The $\mathrm{Cp}$ rings are nearly parallel in both ferrocenyl moieties; the dihedral angle between the rings' mean planes is $3.9(3)^{\circ}$ for $\mathrm{C}-1-\mathrm{C}-5 / \mathrm{C}-6-\mathrm{C}-10$ rings and $3.2(3)^{\circ}$ for $\mathrm{C}-11-\mathrm{C}-15 / \mathrm{C}-16-\mathrm{C}-20$ rings. The dihedral angle between the mean planes of the $\mathrm{C}-1-\mathrm{C}-5$ and $\mathrm{C}-11-\mathrm{C}-15$ rings is $84.8(3)^{\circ}$, which means that the disubstituted and monosubstituted ferrocenyl moieties are almost perpendicular to the each other.

The supramolecular structure contains one very weak $\mathrm{C}-\mathrm{H} \cdots \pi$ interaction between cyclopentadienyl ring hydrogen atom and the $\mathrm{Cp}$ ring of neighboring molecule $\left[\mathrm{H} 14 \cdots \mathrm{Cg}^{i}\right.$ (C-6$\left.\mathrm{C}-10)=2.81 \AA ; \mathrm{C}-14-\mathrm{H} 14 \cdots \mathrm{C}-\mathrm{g}^{i}(\mathrm{C}-6-\mathrm{C}-10)=145^{\circ} ;(i):-1+\mathrm{x}, \mathrm{y}, \mathrm{z}\right]$. This interaction links the molecules of $\mathbf{3}$ into infinite chains parallel to the $a$ axis (Figure 2).

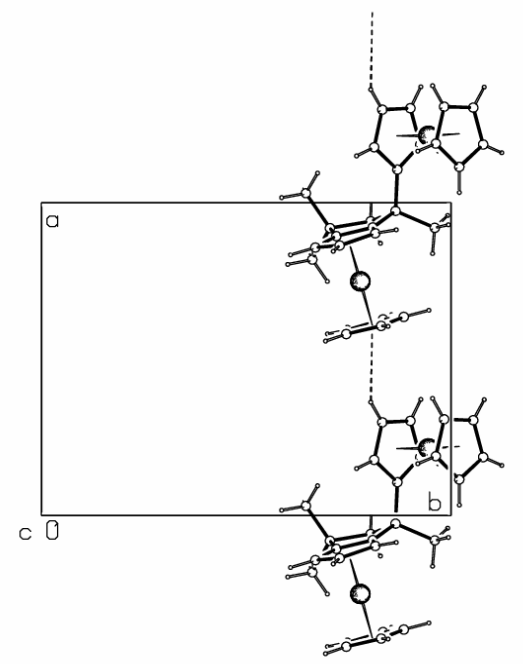

Figure 2. A crystal packing diagram of $\mathbf{4}$, viewed along the $c$ axis, showing the $\mathrm{C}-\mathrm{H} \cdots \pi$ interaction which links the molecules into infinite chains. The $\mathrm{C}-\mathrm{H} \cdots \pi$ interaction is indicated by dotted lines. 


\section{Computational results}

At the BP86/AE1 level of theory only one isomer of $\mathbf{3}$ can be located as stable minima for the product of heteroannular cyclodimerization (Figure 3). The two cyclopentadienyl rings in both ferrocenyl moieties of $\mathbf{3}$ are eclipsed with respect to each other. We have performed optimization with the starting geometry in which relative conformations of corresponding $\mathrm{Cp}$ rings are staggered. However, during geometry optimization, using either BP86 or B3LYP method, staggered conformations converged back to eclipsed ones ( $\mathrm{Cp}$ ring rotation occurs during optimization procedure).

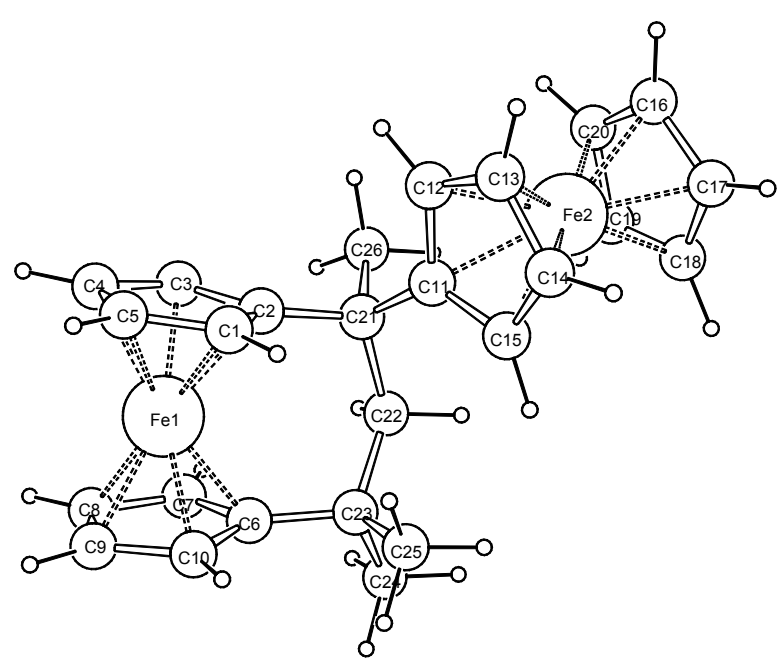

3

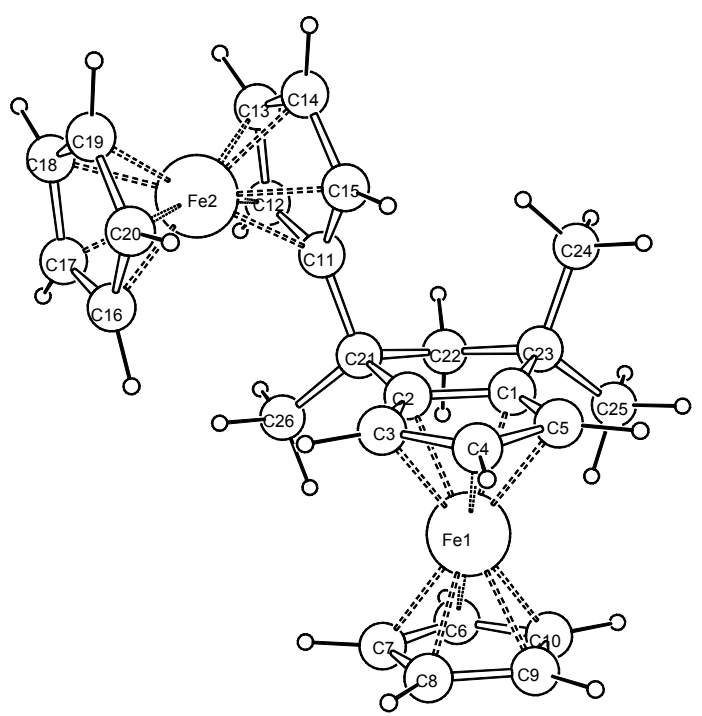

$4 a$

Figure 3. BP86/AE1 optimized geometries of hetero- and homoannular cyclodimerization products 3 and $\mathbf{4 a}$ (the most stable minimum), respectively.

In the case of the homoannular cyclodimerization product 4 three different rotational isomers, with respect to the rotation about the C-11-C-21 bond (atom numbering defined in Figure 1), can be located as stable minima, namely, $\mathbf{4 a}, \mathbf{4 b}$, and $\mathbf{4 c}$ (Scheme 2). In $\mathbf{4 a}$, which is similar to the structure that have been characterized by X-ray crystallography, both the disubstituted ferrocenyl moiety and C-21-methyl group are oriented in an endo-position, i.e., the position below the cyclopentadienyl ring of the mono-substituted ferrocene, whereas structures 4b and 4c are characterized by exo-position of the disubstituted ferrocenyl moiety and exoposition of the C-21-methyl group, respectively. 

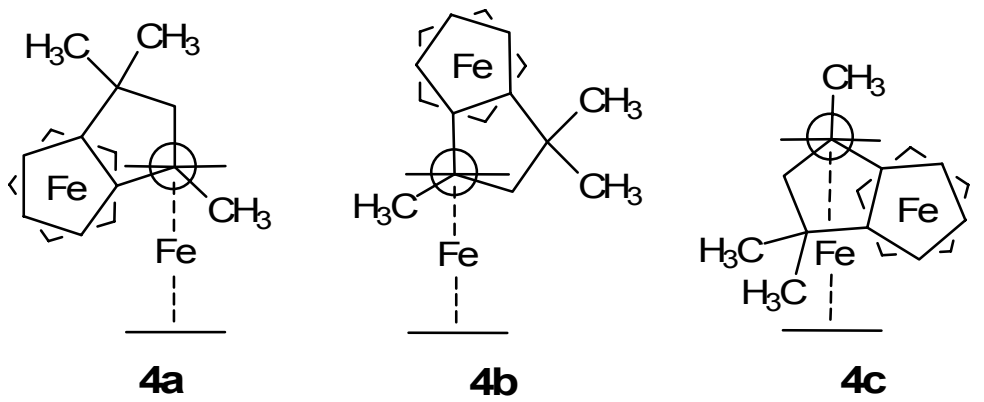

\section{Scheme 2}

These three BP86-optimized conformers span a range of $c a .3 \mathrm{kcal} / \mathrm{mol}$. The most stable isomer in the gas phase was found to be $4 \mathbf{a}$ which correspond to the crystal structure (optimized at the BP86/AE1 level). It is calculated to be 1.8 and $2.9 \mathrm{kcal} / \mathrm{mol}$ more stable than rotamers $\mathbf{4 b}$ and $4 \mathbf{c}$, respectively. If the model solvent (chloroform, $\varepsilon=4.7$ ) is implicitly included by using PCM-BP86 calculations, the isomer $\mathbf{4 a}$ becomes even more stable than $\mathbf{4 b}$ or $\mathbf{4 c}$ (Table 1). Both results from the gas phase and from solvent model calculations are consistent with experimental data, i.e. the most stable structure is $\mathbf{4 a}$ which corresponds to geometry obtained from X-ray analysis.

Transition state structures $\mathbf{T S}_{\mathbf{4 a} 4 \mathbf{b}}$, $\mathbf{T} \mathbf{S}_{\mathbf{4 a 4 c}}$, and $\mathbf{T} \mathbf{S}_{\mathbf{4 b} 4 \mathrm{c}}$ connecting these three minima have been located and each has been characterized by one imaginary frequency which corresponds to the rotation around $\mathrm{C} 11-\mathrm{C}-21$ bond (see Supplementary Material). All calculated energy barriers separating these three different rotamers are below $4 \mathrm{kcal} / \mathrm{mol}$ (Table 1) suggesting fast interconversions between rotamers in equilibrium. However, on the basis of the relative energy differences between the conformers $\mathbf{4 a}, \mathbf{4 b}$ and $\mathbf{4 c}$, one can estimate that relative populations of $\mathbf{4 b}$ and $\mathbf{4 c}$ in the equilibrium mixture are relatively small.

Table 1. Relative energies (in $\mathrm{kcal} / \mathrm{mol}$ ) calculated for structures involved in this study

\begin{tabular}{clll}
\hline Structure & $\Delta \mathrm{E} / \mathrm{BP} 86 / \mathrm{AE} 1$ & $\Delta \mathrm{E} / \mathrm{B} 3 \mathrm{LYP} / \mathrm{AE} 1$ & $\Delta \mathrm{E} / \mathrm{PCM}^{\mathrm{a}}$ \\
\hline $\mathbf{3}$ & 5.1 & 4.9 & 5.4 \\
$\mathbf{4 a}$ & 0.0 & 0.0 & 0.0 \\
$\mathbf{4 b}$ & 1.8 & 1.9 & 2.9 \\
$\mathbf{4 c}$ & 2.9 & 3.0 & 3.3 \\
$\mathbf{T S}_{\mathbf{4 a} 4 \mathbf{b}}$ & 4.0 & - & - \\
$\mathbf{T S}_{\mathbf{4 a 4}}$ & 3.8 & - & - \\
$\mathbf{T S}_{\mathbf{4 b} 4 \mathbf{c}}$ & 3.7 & - & - \\
$\mathbf{4 e}$ & 0.1 & 0.2 & 2.0 \\
$\mathbf{4 t s}$ & 1.2 & 1.2 & 2.1 \\
\hline
\end{tabular}

${ }^{\text {a }}$ BP86/AE1 level: $\varepsilon=4.7$ 
All three isomers of homoannular cyclodimerization product $\mathbf{4}$ are more stable than the main heteroannular cyclodimerization product 3. As expected, the energy barrier for rearrangement of carbocation intermediates, which are involved in formation of $\mathbf{3}$, is lower than the corresponding barrier for carbocation rearrangements leading to $4^{6}$.

The similar calculated geometries of $\mathbf{3}, \mathbf{4 a}, \mathbf{4 b}$, and $\mathbf{4 c}$, and the same relative energies were calculated at the B3LYP/AE1 level of theory. These results are in agreement with earlier findings that the efficiency of the BP86 method and comparable DFT levels have proven quite successful for transition-metal compounds and are well suited for the description of structures, energies, vibrational frequencies, and other properties ${ }^{8}$.

Table 2. ${ }^{13} \mathrm{C}$ - and ${ }^{57} \mathrm{Fe}$ - NMR chemical shifts (in ppm) for $\mathbf{3}$ and rotamers $\mathbf{4 a}$, $\mathbf{4 b}$, and $\mathbf{4 c}$ calculated at the GIAO-B3LYP level (using BP86 geometries)

\begin{tabular}{cllllll}
\hline Atom & $\mathbf{3}$ & Exp. & $\mathbf{4 a}$ & $\mathbf{4 b}$ & $\mathbf{4 c}$ & Exp. \\
\hline C-1 & 71.9 & 68.7 & 101.9 & 104.3 & 104.3 & 101.3 \\
C-2 & 101.3 & 104.1 & 102.6 & 107.8 & 107.1 & 102.5 \\
C-3 & 66.8 & & 60.0 & 58.9 & 59.3 & 63.6 \\
C-4 & 66.5 & $66.4,66.3$, & 69.0 & 68.5 & 68.9 & 68.4 \\
C-5 & 67.3 & 66.1 & 58.3 & 64.3 & 57.9 & 59.5 \\
C-6 & 96.7 & 99.0 & & & & \\
C-7 & 65.7 & & & & & \\
C-8 & 69.0 & $67.8,68.6$, & & & & \\
C-9 & 67.0 & $68.9,69.0$ & $68.2_{\mathrm{av}}$ & $68.0_{\mathrm{av}}$ & $68.6_{\mathrm{av}}$ & $68.9_{a v}$ \\
C-10 & 68.6 & & & & & \\
C-11 & 103.6 & 105.7 & 103.5 & 102.2 & 102.9 & 105.8 \\
C-12/C-15 & $69.2_{\mathrm{av}}$ & $69.0_{a v}$ & 66.9 & 65.7 & 66.9 & 67.4 \\
C-13/C-14 & $65.6_{\mathrm{av}}$ & $68.4_{a v}$ & 65.9 & 66.4 & 65.4 & 65.5 \\
C-16-C-20 & $68.2_{\mathrm{av}}$ & $68.3_{a v}$ & $68.7_{\mathrm{av}}$ & $68.4_{\mathrm{av}}$ & $68.7_{\mathrm{av}}$ & $68.3_{a v}$ \\
Fe-1 & 228.5 & - & 157.5 & 96.2 & 218.3 & - \\
Fe-2 & 639.8 & - & 362.2 & 419.1 & 424.0 & - \\
\hline
\end{tabular}

${ }^{13} \mathrm{C}$ - NMR and ${ }^{57} \mathrm{Fe}$ - chemical shifts for $\mathbf{3}$ and three conformers $\mathbf{4 a}, \mathbf{4 b}$, and $\mathbf{4 c}$ (Table 2) have been calculated at the B3LYP level (using BP86 optimized geometries). Only the calculated ${ }^{13} \mathrm{C}$ - NMR chemical shift values of ferrocenyl moieties were considered for comparison with experimental results. Comparison between experimental and calculated data allow correct assignment for ipso-carbons (C-2, C-6, and C-11 in 3; C-1, C-2, and C-11 in 4), but also for C-3, $\mathrm{C}-4$ and $\mathrm{C}-5$ atoms in 4 . Due to relatively small difference of ${ }^{13} \mathrm{C}$ - NMR chemical shifts calculated for different structures, it is difficult to predict which rotamer of $\mathbf{4}$ is the most abundant in the equilibrium. As the time scale of the NMR spectroscopy is not sufficiently fast for detection of individual constituents of an equilibrium mixture, the rotamers $\mathbf{4 a}, \mathbf{4 b}$ and $\mathbf{4 c}$ cannot be resolved neither by experimental NMR method (only averaged ${ }^{13} \mathrm{C}$ - signal can be 
obtained) unless separated by large barriers (see above). However, relatively large range of ${ }^{57} \mathrm{Fe}$ NMR chemical shifts (from 96.2 to 424.0 ppm) is calculated for different rotamers $\mathbf{4 a}, \mathbf{4 b}$ and $\mathbf{4 c}$, suggesting that ${ }^{57} \mathrm{Fe}$ - NMR could be a sensitive tool to probe the preferred structure in the equilibrium.

Thus, a new isomer 4e having both ferrocenyl moieties with eclipsed conformation is located. At the BP86 level it is calculated only $0.1 \mathrm{kcal} / \mathrm{mol}$ less stable than $4 \mathbf{a}$ in the gas phase, but in the model solvent it is for $2.0 \mathrm{kcal} / \mathrm{mol}$ less stable (Table 1). We have calculated the transition state structure 4ts for the rotation of the $\mathrm{Cp}$ ring in the mono-substituted ferrocenyl moiety. It is characterized by one imaginary frequency of $45 i \mathrm{~cm}^{-1}\left(28 i \mathrm{~cm}^{-1}\right.$ at B3LYP/AE1 level) which corresponds to the $\mathrm{Cp}$ ring rotation. These results are in accord with the low barrier for rotation (ca. $1 \mathrm{kcal} / \mathrm{mol}$ at the BP86 level) calculated for ferrocene itself. ${ }^{9}$ Finally, we have tried several starting geometries with different cyclopentyl moiety conformation, but all these starting structures converged back to cyclopentyl ring conformation as characterized by X-ray crystallography.

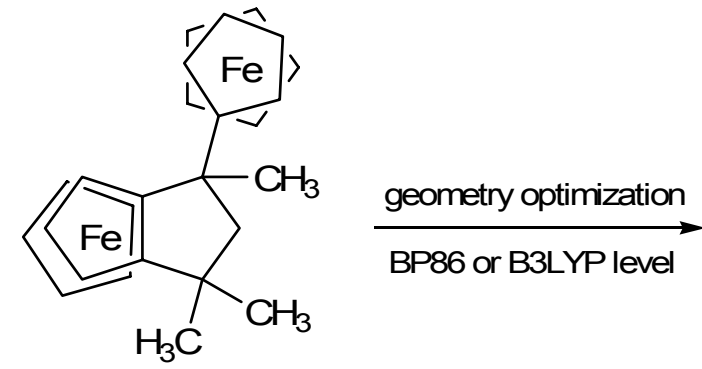

4d

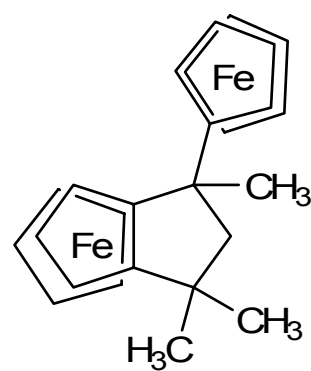

$4 e$

\section{Scheme 3}

In conclusion, it is shown that at least three different geometries are to be considered in order to fully describe structural properties of the product 4. Both B3LYP and BP86 density functional models are capable to reproduce experimental results. The crystal structure obtained by X-ray is supported by quantum-chemical methods which calculated the corresponding rotamer $\mathbf{4 a}$ as the most stable conformer, possibly in solution as well. The experimental ${ }^{13} \mathrm{C}$ NMR chemical shifts for 3 and $\mathbf{4}$ (equilibrium mixture of $\mathbf{4 a}, \mathbf{4 b}$, and $\mathbf{4 c}$ ) obtained in $\mathrm{CDCl}_{3}$ are reproduced by GIAO-B3LYP approach. ${ }^{57} \mathrm{Fe}$ NMR experimental data are needed in order to distinguish three different rotamers of 4. 


\section{Experimental Section}

General. 2-Ferrocenylpropan-2-ol 1 was obtained according to the literature procedure.,6 Products were purified by preparative thin layer chromatography on silica gel (Merck, Kieselgel $60 \mathrm{HF}_{254}$ ) using the mixture $\mathrm{CH}_{2} \mathrm{Cl}_{2}$ /EtOAc. Melting point was determined with a Buechi apparatus. An IR spectrum was recorded as $\mathrm{CH}_{2} \mathrm{Cl}_{2}$ solution with a Bomem MB 100 mid FT-IR spectrophotometer. ${ }^{1} \mathrm{H}$ - and ${ }^{13} \mathrm{C}-\left\{{ }^{1} \mathrm{H}\right\}$-NMR spectra was recorded on a Varian Gemini 300 spectrometer in $\mathrm{CDCl}_{3}$ solution with $\mathrm{Me}_{4} \mathrm{Si}$ as internal standard.

Preparation of 1,2-(1-ferrocenyl-1,3,3-trimethylpropane-1,3-diyl)ferrocene (4). Acetylferrocene $(100 \mathrm{mg}, 0.438 \mathrm{mmol})$ in benzene $(2 \mathrm{ml})$ was added over $30 \mathrm{~min}$ to a refluxing solution of methyl magnesium iodide $(4.385 \mathrm{mmol})$ in diethyl ether $(2 \mathrm{ml})$. The reaction mixture was refluxed for $20 \mathrm{~min}$, cooled, and quenched in ice water. The organic phase was separated, washed with water, dried with $\mathrm{Na}_{2} \mathrm{SO}_{4}$, and evaporated in vacuo. The crude product was dissolved in dry benzene and added acid $\mathrm{Al}_{2} \mathrm{O}_{3}$. The solution was refluxed $1.5 \mathrm{~h}$ with continuous removal of water (Dean-Stark apparatus). The mixture was filtered and the solvent evaporated off. TLC-purification with $\mathrm{CH}_{2} \mathrm{Cl}_{2} / \mathrm{EtAc}(10: 1)$ gave $50 \mathrm{mg}$ (60\%) of 2-ferrocenylprop-1-ene 2 and $60 \mathrm{mg}$ of $\mathbf{3}$ and $\mathbf{4}$ (viscous orange oil, total yields $30 \%$, the relative yields of $\mathbf{3}$ and $\mathbf{4}$ based on NMR spectrum were 60 and 30\%, respectively). Crystallization in dichloromethane gave orange crystal of 4 ; mp $184-186{ }^{\circ} \mathrm{C}$ (lit. $\left.{ }^{6 a} \mathrm{mp} 185-186{ }^{\circ} \mathrm{C}\right)$. IR $\left(\mathrm{CH}_{2} \mathrm{Cl}_{2}\right): v_{\max }=3097 \mathrm{w}(\mathrm{C}-\mathrm{H})$ arom., $2926 \mathrm{~m}, 2863 \mathrm{~m}(\mathrm{C}-\mathrm{H})$ aliph., $1463 \mathrm{w}\left(\mathrm{CH}_{3}, \mathrm{CH}_{2}\right), 1366\left(\mathrm{C}\left(\mathrm{CH}_{3}\right)_{2}\right) \mathrm{cm}^{-1}$.

1,1'-(1-Ferrocenyl-1,3,3-trimethylpropane-1,3-diyl)ferrocene (3). ${ }^{1} \mathrm{H}$ NMR $(300 \mathrm{MHz}$, $\left.\mathrm{CDCl}_{3}\right): \delta 4.38(\mathrm{~m}, 1 \mathrm{H}, \mathrm{Cp}-\mathrm{H}), 4.21(\mathrm{~m}, 1 \mathrm{H}, \mathrm{Cp}-\mathrm{H}), 4.19(\mathrm{~m}, 2 \mathrm{H}, \mathrm{Cp}-\mathrm{H}), 4.18$ (s, 5H, Cp unsubst.), 4.14 (m, 1H, Cp-H), 3.96 (m, 1H, Cp-H), 3.88 (m, 4H, Cp-H), 3.72 (m, 1H, Cp-H), 3.54 (m, 1H, $\mathrm{Cp}-\mathrm{H}), 2.81\left(\mathrm{~d}, 1 \mathrm{H}, \mathrm{CH}_{2}\right), 2.07\left(\mathrm{~d}, 1 \mathrm{H}, \mathrm{CH}_{2}, J=12.9 \mathrm{~Hz}\right), 1.60\left(\mathrm{~s}, 3 \mathrm{H}, \mathrm{CH}_{3}\right), 1.50\left(\mathrm{~s}, 3 \mathrm{H}, \mathrm{CH}_{3}\right)$, 1.25 (s, 3H, $\left.\mathrm{CH}_{3}\right)$ ppm. 1,2-(1-ferrocenyl-1,3,3-trimethylpropane-1,3-diyl)ferrocene (4). ${ }^{1} \mathrm{H}$

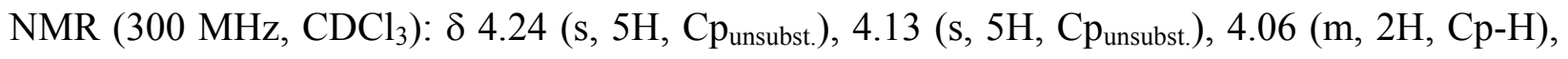
4.04 (m, 1H, Cp-H), 4.02 (m, 1H, Cp-H), 3.91 (m, 1H, Cp-H), 3.87 (m, 1H, Cp-H), 3.38 (m, 1H, $\mathrm{Cp}-\mathrm{H}), 2.48\left(\mathrm{~d}, 1 \mathrm{H}, \mathrm{CH}_{2}\right), 1.94\left(\mathrm{~d}, 1 \mathrm{H}, \mathrm{CH}_{2}, J=12.4 \mathrm{~Hz}\right), 1.91\left(\mathrm{~s}, 3 \mathrm{H}, \mathrm{CH}_{3}\right), 1.36\left(\mathrm{~s}, 3 \mathrm{H}, \mathrm{CH}_{3}\right)$, $0.86\left(\mathrm{~s}, 3 \mathrm{H}, \mathrm{CH}_{3}\right) \mathrm{ppm}$.

\section{X-Ray determination of 4}

Single crystal of 4 suitable for X-ray single crystal analysis was obtained at room temperature by partial evaporation from a mixture of dichloromethane, methanol and n-hexane (1:1:1). The orange prismatic crystal with dimensions 0.326 × $0.428 \times 0.534 \mathrm{~mm}^{3}$ was selected for X-ray structure analysis. The intensities were collected at $295 \mathrm{~K}$ on a Oxford Diffraction Xcalibur2 diffractometer using graphite-monochromated $\operatorname{Mo} K_{\alpha}$ radiation $(\lambda=0.71073 \AA)$ and $\omega$-scan mode. The data collection and reduction were carried out with the CrysAlis ${ }^{10}$ programs. The intensities were corrected for Lorentz and polarization effects and for absorption using the multiscan absorption correction method (CrysAlis $R E D^{10}$ ). The crystal structure was solved by direct 
methods. All non-hydrogen atoms were refined anisotropically by full-matrix least-squares calculations based on $F^{2}$. All hydrogen atoms were treated using appropriate riding models. For structure solution, refinement and analysis were used the following programs: SHELXS97, ${ }^{11}$ SHELXL97 ${ }^{12}$ and PLATON. ${ }^{13}$ The molecular structure drawing was prepared by the PLATON ${ }^{13}$ program. CCDC 764215 contains the supplementary crystallographic data for this Paper. These data can be obtained free of charge from The Cambridge Crystallographic Data Centre via www.ccdc.cam.ac.uk/data_request/cif. Crystal data: $\mathrm{C}_{26} \mathrm{H}_{28} \mathrm{Fe}_{2}, M_{\mathrm{r}}=452.18$, orthorhombic space group $P$ bca (No. 61); $a=11.344(2), b=14.678(2), c=24.621(4) \AA, V=4099.6(11) \AA^{3} ; Z=8$; $\mu\left(\mathrm{MoK}_{\alpha}\right)=1.424 \mathrm{~mm}^{-1} ; \mathrm{R}_{\mathrm{Int}}=0.0235 ; S=0.904 ; R / w R=0.0473 / 0.1602$ for 256 parameters and 3860 reflections with $I \geq 2 \sigma(I), R / w R=0.0598 / 0.1784$ for all 4442 independent reflections measured in the range $7.88^{\circ}-2 \theta-54.00^{\circ}$.

\section{Computational details}

Geometries were fully optimized at the RI-BP86 level as implemented in the G03 program ${ }^{14}$, employing the exchange and correlation functions of Becke ${ }^{15}$ and Perdew16, respectively, together with a fine integration grid (75 radial shells with 302 angular points per shell), the augmented Wachters' basis ${ }^{17}$ on $\mathrm{Fe}(8 \mathrm{~s} 7 \mathrm{p} 4 \mathrm{~d})$ and $6-31 \mathrm{G}^{*}$ basis on all other elements (denoted AE1 in previous work), and suitable auxiliary basis sets for the fitting of the Coulomb potential. For comparison, the B3LYP functional was used, which combines Becke's three-parameter exchange functional with the correlation functional of Lee, Yang, and Parr ${ }^{18}$. Harmonic frequencies were computed from analytical second derivatives. Relative energy differences are calculated with ZPE correction included. IRC calculations (intrinsic reaction coordinate as implemented in Gaussian 03) were performed at the corresponding level of theory to identify the minima connected through transition state. Test calculations for selected substrates at the RIBP86 and at the BP86 level (i.e. without density fitting) confirmed that geometrical parameters and harmonic vibrations were essentially identical with both approaches. This and similar DFT levels have proven to be reliable for calculating structures, molecular energetics and dynamics of organometallics in general, and metallocene compounds in particular. ${ }^{19}$

Magnetic shieldings $(\sigma)$ were computed at the B3LYP level for the RI-BP86 equilibrium geometries, employing GIAOs (gauge including atomic orbitals) ${ }^{20}$ and basis $\mathrm{II}^{\prime}$, i.e., the augmented Wachters basis ${ }^{21}$ which is essentially of polarized triple- $\xi$ quality, on $\mathrm{C}$ - and $\mathrm{O}-$, and IGLO-DZ basis on hydrogen. Chemical shifts were calculated relative to ferrocene $\left({ }^{57} \mathrm{Fe},{ }^{13} \mathrm{C}\right.$, and ${ }^{1} \mathrm{H}$ - magnetic shieldings $-4372.8,106.2$, and $28.1 \mathrm{ppm}$ at the same level), and the ${ }^{13} \mathrm{C}-,{ }^{1} \mathrm{H}$-, and ${ }^{57} \mathrm{Fe}$ - chemical shifts were converted to the usual standards, TMS and $\mathrm{Fe}(\mathrm{CO})_{5}$, using the experimental $\delta\left({ }^{13} \mathrm{C}\right), \delta\left({ }^{1} \mathrm{H}\right)$, and $\delta\left({ }^{57} \mathrm{Fe}\right)$ values of ferrocene, 67.8, 4.2, and $1532 \mathrm{ppm}$, respectively ${ }^{22}$. This level has been shown to perform very well for transition-metal chemical shifts, including ${ }^{57} \mathrm{Fe}$, where further enlargement of the basis set in the NMR part has afforded only minor changes in the computed values. ${ }^{8 b, 23}$ 
Solvent model calculations were performed at the BP86/AE1 level employing the polarizable continuum model (PCM) of Tomasi and co-workers 24 (using parameters of chloroform, i.e., solvent relative permittivity $\varepsilon=4.7)$.

\section{Acknowledgements}

This research was supported by the Ministry of Science, Education and Sports of the Republic of Croatia (Grant Nos. 058-1191344-3122 and 119-1193079-3069.)

\section{References and Notes}

1. (a) Patti, A.; Pedotti, S. Tetrahedron: Asymmetry 2003, 14, 597. (b) Patti, A.; Nicolosi, G. Tetrahedron: Asymmetry 2000, 11, 815.

2. Enders, D.; Peters, R.; Lochtman, R.; Raabe, G. Angew. Chem., Int. Ed. Engl. 1999, 38, 2421.

3. Lapić, J.; Rapić, V. Croat. Chem. Acta 2000, 73, 755.

4. Đaković, S.; Lapić, J.; Rapić, V. Biocatal. Biotransfor. 2003, 21, 291.

5. Goldberg, S. I.; Loeble, W. D.; Tidwell, T. T. J. Org. Chem. 1967, 32, 4070.

6. (a) Horspool, W. N.; Sutherland, R. G.; Sutton, J. R. Can. J. Chem. 1970, 48, 3542. (b) Horspool, W. N.; Sutherland, R. G.; Sutton, J. R. Can. J. Chem. 1969, 47, 3085. (c) Sterzo, C. L.; Ortaggi, G. Chem. Soc., Perkin Trans 2 1984, 345.

7. Mendez Iturbide, D.; Klimova, E. I.; Martinez Garcia, M.; Klimova, T.; Martinez Mendoza, J. M.; Alvarez Toledano, C.; Ruben Toscano, A.; Ruiz Ramirez, L. J. Organomet. Chem. 2002, 645, 183.

8. (a) Koch, W.; Holthausen, M. C. A Chemist's Guide to Density Functional Theory; WileyVCH: Weinheim, 2000, and the extensive bibliography therein. (b) Vrček, V.; Bühl, M. Organometallics 2006, 25, 358. (c) Bühl, M.; Kabrede, H. J. Chem. Theory Comput. 2006, $2,1282$.

9. Bühl, M.; Grigoleit, S. Organometallics 2005, 24, 1516.

10. Oxford Diffraction, Xcalibur CCD System. CrysAlis CCD and CrysAlis RED. Versions 1.171.31.5. Oxford Diffraction, Oxford, United Kingdom, 2006.

11. Sheldrick, G. M. SHELXS97. Program for the Solution of Crystal Structures, University of Göttingen, Germany, 1997.

12. Sheldrick, G. M. SHELXL97. Program for the Refinement of Crystal Structures, University of Göttingen, Germany, 1997.

13. Spek, A. L. J. Appl. Crystallogr. 2003, 36, 7.

14. Frisch, M. J.; Trucks, G. W.; Schlegel, H. B.; Scuseria, G. E.; Robb, M. A.; Voth, J. R.; Salvador, P.; Dannenberg, J. J.; Zakrzewski, V. G.; Dapprich, S.; Daniels, A. D.; Strain, M. 
C.; Farkas, O.; Malick, D. K.; Rabuck, A. D.; Raghavachari, K.; Foresman, J. B.; Ortiz, J. V.; Cui, Q.; Baboul, A. G.; Clifford, S.; J. Cioslowski, J.; Stefanov, B. B.; Liu, G.; Liashenko, A.; Piskorz, P.; Komaromi, I.; Martin, R. L.; Fox, D. J.; Keith, T.; Al-Laham Cheeseman, M. A.; Montgomery Jr., J. A.; Vreven, T.; Kudin, K. N.; Burant, J. C.; Millam, J. M.; Iyengar, S. S.; Tomasi, J.; Barone, V.; Mennucci, B.; Cossi, M.; Scalmani, G.; Rega, N.; Petersson, G. A.; Nakatsuji, H.; Hada, M.; Ehara, M.; Toyota, K.; Fukuda, R.; Hasegawa, J.; Ishida, M.; Nakajima, T.; Honda, Y.; Kitao, O.; Nakai, H.; Klene, M.; Li, X.; Knox, J. E.; Hratchian, H. P.; Cross, J. B.; Adamo, C.; Jaramillo, J.; Gomperts, R.; Stratmann, R. E.; Yazyev, O.; Austin, A. J.; Cammi, R., Pomelli, C.; Ochterski, J. W.; Ayala, P. Y.; Morokuma, K.; Peng, C. Y.; Nanayakkara, A.; Challacombe, M.; Gill, P. M. W.; Johnson, B.; Chen, W.; Wong, M. W.; Gonzalez, C.; Pople, J. A. Gaussian 03, Gaussian, Inc., Pittsburgh PA, 2003.

15. Becke, A. D. Phys. Rev. A 1988, 38, 3098.

16. Perdew, J. P. Phys. Rev. B 1986, 33, 8822.

17. Wachters, A. J. H. J. Chem. Phys. 1970, 52, 1033. (b) Hay, P. J. J. Chem. Phys. 1977, 66, 4377.

18. Hehre, W. J.; Ditchfield, R.; Pople, J. A. J. Chem. Phys. 1972, $56,2257$.

19. (a) Ziegler, T. Can. J. Chem. 1995, 73, 743. (b) Mayor-Lopez, M. J.; Weber, J.; Mannfours, B.; Cunningham Jr., A. F. Organometallics 1998, 17, 4983. (c) Berces, A.; Ziegler, T. Top. Curr. Chem. 1996, 182, 41.

20. Wolinski, K.; Hinton, J. F.; Pulay, P. J. Am. Chem. Soc. 1990, 112, 8251. GIAO-DFT implementation: Cheeseman, J. R.; Trucks, G. W.; Keith, T. A.; Frisch, M. J. J. Chem. Phys. 1996, 104, 5497.

21. Wachters, A. J. H. J. Chem. Phys. 1970, 52, 1033. (b) Hay, P. J. J. Chem. Phys. 1977, 66, 4377 on Fe, IGLO-basis II, Kutzelnigg, W.; Fleischer, U.; Schindler, M. In NMR Basic Principles and Progress; Springer-Verlag: Berlin, 1990; Vol. 23, pp 165-262.

22. For experimental ${ }^{57}$ Fe NMR data: Haslinger, E.; Robin, W.; Schloegel, K.; Weissensteiner, W. J. Organomet. Chem. 1981, 218, C11. For experimental ${ }^{13} \mathrm{C}$ and ${ }^{1} \mathrm{H}$ NMR data: Spectral Database for Organic Compounds SDBS, accessed at http://riodb.ibase.aist.go.jp.

23. (a) Bühl, M. Chem. Phys. Lett. 1997, 267, 251. (b) Šarić, A.; Vrček, V.; Bühl, M. Organometallics 2008, 27, 394.

24. As implemented in Gaussian03: (a) Barone, V.; Cossi, M.; Tomasi, J. J. Comput. Chem. 1998, 19, 404. (b) Cossi, M.; Scalmani, G.; Rega, N.; Barone, V. J. Chem. Phys. 2002, 117, 43. (c) Cossi, M.; Crescenzi, O. J. Chem. Phys. 2003, 19, 8863. 